\title{
DiversidADE CULTURAL, PLURALIDADE, DIFERENÇA: QUAL É A QUESTÃO?
}

\author{
Daniele Pechuti Kowalewski ${ }^{1}$ \\ e Flávia Schilling ${ }^{2}$
}

\begin{abstract}
Resumo
0 presente artigo busca discutir a presença, na educação brasileira, da questão das diversidades culturais tornadas necessidades curriculares. Para melhor entender essa questão, analisamos sua emergência através de alguns documentos federais - Tema transversal Pluralidade Cultural, nos PCN, As Diretrizes Curriculares Nacionais para a Educação das Relações Étnico-Raciais e para o Ensino de História e Cultura Afro-Brasileira e Africana o o Programa Ética e Cidadania: construindo valores na escola e na sociedade, visando reconhecer as conexões estabelecidas nos citados documentos com as lutas contemporâneas vinculadas ao reconhecimento identitário. Trata-se de traçar um paralelo, mesmo que inicial, entre tais lutas e questões da democracia contemporânea, a partir das noções de desentendimento em Jacques Rancière e de poderes e direitos em Michel Foucault.
\end{abstract}

Palavras-chave: Currículo. Democracia. Diversidades culturais. Foucault. Rancière.

\footnotetext{
${ }^{1}$ Doutoranda e Mestre em Sociologia da Educação pela Universidade de São Paulo. Formação em Ciências Sociais, História e Filosofia. Professora e Pesquisadora. danielepk@ig.com.br

${ }^{2}$ Professora da Faculdade de Educação da Universidade de São Paulo. oak1@uol.com.br
} 


\section{CULTURAL DIVERSITY, PLURALITY, DIFFERENCE: WHAT IS THE POINT?}

\section{Abstract}

This article discusses an increasingly more present shift in Brazilian education: cultural diversities that have become curricular needs. In order to better understand this issue, we analyze its emergence through some federal documents - Transversal theme Cultural Plurality, in the PCNs (National Curricular Guidelines), National Curriculum Guidelines for Ethnic-Racial Relations and for Teaching Afro-Brazilian and African History and Culture and the Ethics and Citizenship Program: constructing values at school and in society - aimed at recognizing connections established in the cited documents with the contemporary struggles linked to the recognition of identity. It is an attempt to draw a parallel between such struggles and contemporary democracy issues, based on the misunderstanding notions in Jacques Rancière and powers and rights in Michel Foucault.

Keywords: Curriculum. Democracy. Cultural diversities. Foucault. Rancière.

\section{INTRODUÇÃO - A CONSTITUIÇÃO DA DIVERSIDADE CULTURAL COMO PROBLEMA CURRICULAR: NOVOS DILEMAS, NOVAS VOZES}

escola brasileira baseia-se em princípios universalistas ou particularistas?
Enaltece a igualdade ou a diferença? Somos capazes de lidar com as
múltiplas diversidades - culturais, raciais, religiosas, de gênero, sexualidade, estilos de vida etc - no ambiente escolar? E nossos materiais didáticos, respondem a tamanha diversidade?

Essas difíceis perguntas refletem mudanças, ainda em curso. Novos objetivos aparecem na educação brasileira no que se refere ao currículo e, consequentemente, às práticas pedagógicas. Pode-se notar, principalmente a partir da abertura política (1985), alterações nos propósitos curriculares, que incluem a inserção das questões relacionadas a nossa identidade nacional, cultural, étnica, racial.

Pretende-se, neste artigo, tratar, especificamente, da inserção de temas ligados à diversidade cultural e racial como obrigatórios nos currículos e projetos pedagógicos. Essa inserção é fruto de toda uma mudança ocorrida na cena 
política, principalmente a partir das décadas de 60 e 70, quando Movimentos Sociais conquistaram, dentre outras reivindicações, o reconhecimento cultural. São lutas que parecem se dar em torno de valores imateriais, o que denota uma diferença em relação às demandas de classe apresentadas por diferentes setores trabalhistas. Movimentos como o feminista, negro, homossexual, ecologista, dentre outros, tomam o espaço público para serem ouvidos em suas indignações. Embora isso tenha ocorrido de forma diferente em diversas partes do mundo, pode-se notar um fator comum: uma mudança ou deslocamento de foco nas lutas a partir de então: as lutas passam a ocorrer não são somente por demandas redistribuitivas, há também um novo alvo, o reconhecimento das diferenças das intituladas minorias. ${ }^{3}$

Várias questões relacionadas às minorias, aqui no Brasil, só tiveram destaque a partir das discussões que antecederam a Constituição de 1988, como as vinculadas à discriminação racial. É notável que no Brasil, em que a diversidade cultural é inegável - por conta de seu passado colonial, escravocrata e sua miscigenação - demandas como o reconhecimento cultural ou a liberdade religiosa ganhem um relevo todo específico. Notadamente, as discussões sobre os conteúdos curriculares obrigatórios na educação brasileira, fazem parte das demandas de grupos e setores sociais interessados em evidenciar seus reclames. Se, até então, nossos livros didáticos apareciam recheados de alegorias homogeneizadoras da sociedade brasileira, a luta política agora supunha elucidar as diferenças que compõem nossa sociedade, para expor como somos dessemelhantes em nossas culturas, raças e desigualdades econômicas.

Em 1998, com a Publicação dos Temas Transversais nos Parâmetros Curriculares Nacionais (PCN), o tema da Pluralidade Cultural aparece, não pela primeira vez, mas como questão de grande importância para a educação brasileira, ao lado de outros como Ética, Saúde, Meio-ambiente, Educação Sexual, além de Trabalho e Consumo (BRASIL, 1998). Com vistas à consolidação do espírito democrático e a formação de uma identidade nacional que se compõe e repõe constantemente, o documento federal sobre a Pluralidade Cultural, nos PCN, baseia-se, principalmente, nos princípios da Constituição Brasileira (1988), no Estatuto da Criança e Adolescente (1992), na Declaração Universal dos Direitos Humanos (1948) e na Conferência de Viena (1993).

\footnotetext{
${ }^{3}$ Entendemos por minorias setores da sociedade que sofreram ou sofrem algum desprivilégio, não necessariamente grupos em menor número.
} 
A tentativa é de estabelecer uma sociedade mais justa e democrática, partindo de um Estado laico que garanta a liberdade de consciência quanto a etnias e religiões (BRASIL, 1998, p. 30). Esse objetivo é pensado a partir de uma concepção de sociedade que busca explicitar a diversidade étnica e cultural que a compõe, compreendendo suas relações, marcadas por desigualdades socioeconômicas, e com vistas às transformações necessárias que levem em conta a diferenciação entre desigualdade social e a diferença entre culturas (BRASIL, 1998, p. 19-21).

Outro documento federal sobre educação imprescindível para entendermos essa mudança curricular são As Diretrizes Curriculares Nacionais para a Educação das Relações Étnico-Raciais e para o Ensino de História e Cultura Afro-Brasileira eAfricana que objetivam, principalmente, "oferecer uma resposta, entre outras, na área da educação, à demanda da população afrodescendente, no sentido de políticas de ações afirmativas, isto é, de políticas de reparações, e de reconhecimento e valorização de sua história, cultura, identidade" (BRASIL, 2004).

Trata-se de uma "política curricular, fundada em dimensões históricas, sociais, antropológicas oriundas da realidade brasileira, e busca combater o racismo e as discriminações que atingem particularmente os negros". Nesta perspectiva, "propõe a divulgação e produção de conhecimentos, a formação de atitudes, posturas e valores que eduquem cidadãos orgulhosos de seu pertencimento étnicoracial - descendentes de africanos, povos indígenas, descendentes de europeus, de asiáticos - para interagirem na construção de uma nação democrática, em que todos, igualmente, tenham seus direitos garantidos e sua identidade valorizada" (BRASIL, 1998, p. 10).

Nota-se, no referido documento, uma resposta às indagações, principalmente do(s) Movimento(s) Negro(s), que deram origem à lei 10.639/03, tornando obrigatório o ensino de história e cultura afro-brasileira e africana nas escolas de todo o país. Em 2008, outra lei, a 11.645, fez o mesmo com relação aos povos indígenas.

Com foco diferente do tema Pluralidade Cultural - que não trata de uma cultura específica, embora cite com maior frequência os negros e indígenas - essas Diretrizes constituem, como justificativa, a "demanda da comunidade afro-brasileira por reconhecimento, valorização e afirmação dos direitos, no que diz respeito à educação" (BRASIL, 1998, p. 11) para a construção de uma 
nação democrática, em uma sociedade multiracial e pluriética, que não troque simplesmente o foco "etnocêntrico marcadamente de raiz européia por um africano", mas que amplie "o foco dos currículos escolares para a diversidade cultural, racial, social e econômica brasileira” (BRASIL, 1998, p. 17).

Em 2007, outro documento federal é publicado sobre essa temática: 0 Programa Ética e Cidadania: construindo valores na escola e na sociedade (BRASIL, 2007). Tal documento não é um "parâmetro" ou uma "diretriz", mas um programa de adesão voluntária por parte das escolas interessadas na constituição de um fórum ético permanente, que vise o convívio democrático através de ações efetivas ocorridas no âmbito escolar, de forma não centralizada, não linear e não hierarquizada. Em tal documento, a democracia e a cidadania também são os valores essenciais, e o entendimento entre as relações éticas e educação aparece como fundamental na luta pela construção de uma sociedade mais justa. Aqui, o tema da diversidade cultural é tratado junto às especificidades de gênero, pois, segundo o documento, a sociedade brasileira constitui-se de forma "eurocêntrica e androcêntrica". A ideia central para o funcionamento do fórum de cidadania é a de que essa situação seja tratada com a comunidade, dialogando com a realidade cotidiana e com as normas sociomorais, no desenvolvimento de "ações que se contraponham às exclusões, preconceitos e discriminações advindos das distintas formas de deficiência, diferenças sociais, econômicas, psíquicas, físicas, culturais, religiosas, raciais, ideológicas e de gênero" (BRASIL, 2007, p. 15).

Temos, assim, a construção de um paradoxo ou de uma tensão conceitual e política sobre a possibilidade de vinculação entre concepções universalistas dos direitos e os particularismos culturais, resultantes de visões relativistas. Melhor explicando, a tensão dar-se-ia na tentativa de conciliação entre os princípios, que parecem irredutíveis: de um lado a igualdade absoluta e de outro, critérios diferenciadores entre cada cultura e/ou raça, gênero, religião, etc.

Para melhor compreendermos como essas questões sobre a pluralidade/ diversidade das culturas ganham cada vez mais destaque no cenário político atual e, consequentemente, naeducação brasileira, propõe-se sua aproximação com duas diferentes leituras sobre as lutas e conquistas de direitos na contemporaneidade. Trata-se de uma análise de algumas ideias dos pensadores franceses Jacques Rancière (1940) e Michel Foucault (1926-1984). Não se pretende uma leitura pormenorizada de seus conceitos ou explicar suas formas de análise, mas de utilizar seus diagnósticos para melhor entendermos de que forma a inserção 
política dessas demandas identitárias/culturais podem ser vistas como um tipo de ação política.

\section{DA POLÍTICA À DEMOCRACIA HUMANITÁRIA:}

\section{A DISPOSIÇÃO DOS SERES FALANTES NA ESFERA PÚBLICA}

Jacques Rancière (1996) apresenta-nos um cuidadoso e crítico olhar de como as ações políticas vinculam-se, cada vez mais, a grupos identitários. Para explicar esse fenômeno, o autor delineia em sua obra $O$ desentendimento: política e filosofia, um reexame da democracia, procurando compreender como 0 poder é pensado e como se constitui a política democrática hoje.

Rancière, analisando a constituição do campo da política, e em especial a Democracia - desde seu surgimento na Antiguidade Clássica Grega - percebe que a política mesma só passa a ter razão de ser a partir daqueles excluídos do espaço público institucionalizado, os que não têm acesso à palavra, os sem-parcela, o demos, em contraposição aos "poderosos", que podem falar publicamente. É devido àqueles que sofrem "dano", uma condição desprivilegiada frente aos demais de certa sociedade, que a política existe como tentativa de adequação e coesão social.

Se para os gregos, a diferença específica, conforme afirmara Aristóteles, do homem em relação a outros seres é o logos, que se expressa na "palavra", a negação do direito à fala no espaço público daqueles menos privilegiados constitui a própria negação da humanidade dos menos favorecidos. Os destituídos de palavra, aos buscarem ser ouvidos em suas reivindicações, fazem com que a ordenação social seja abalada, e é esse constante perigo inerente a toda e qualquer sociedade desigual que torna necessária a dinâmica da política.

Ao mostrar o paradoxo da política, ou seja, a falta de um fundamento que lhe seja próprio, Rancière (1996, p. 20-30), analisa como a luta política se faz por uma torção constitutiva que impede o curso natural das coisas, instituindo-a como território do dano, e não da igualdade, condição criada e impossibilitada pela própria política. Os ricos continuam, segundo o autor, desde a Antiguidade até hoje conclamando que não há parcela dos sem-parcela, negando com isso a própria concepção da política. Já nos eufemismos contemporâneos, a proposta enuncia-se de outra forma: a sociedade é dividida em partes. Em seus termos, "maiorias e minorias sociais, "categorias sócio-profissionais, grupos de interesses, 
comunidades, etc. Há partes, das quais devemos fazer parceiros" (RANCIÈRE, 1996, p. 29).

0 efeito disso, para Rancière, é que raramente temos política, pois esta só existe através da igualdade, princípio este que não lhe é próprio (RANCIÈRE, 1996, p. 45). De tal modo, a política está diretamente vinculada ao poder do logos e da palavra, ou melhor, dos que são reconhecidos para 'serem' ouvidos e contados, a repartição dos corpos falantes. Do contrário há enfrentamento por conta dessa separação entre as partes sociais, é por isso que política e polícia são definições sempre amarradas como configuração conflituosa do comum, sendo esta última uma regra do aparecer dos corpos, uma configuração das ocupações e das propriedades dos espaços distribuídos, suas funções, lugares, identidades, etc. (RANCIÈRE apud NATERCIA, 2005, p. 16).

A possibilidade desse dialoguismo múltiplo sobre um litígio é o que compõe a política. Esse dissenso decorre daquilo que Ranciére define como desentendimento, algo muito diferente de posições simplesmente antagônicas, mas que sugere "um tipo determinado de situação da palavra: aquela em que um dos interlocutores ao mesmo tempo entende e não entende o que diz o outro". Não sendo conflito entre aquele que diz branco e aquele que diz preto, mas sim, entre aquele que diz branco e aquele que diz branco mas não entendem a mesma coisa, ou não entende de modo nenhum que o outro diz a mesma coisa com o nome de brancura. Essas disputas constituem "a própria racionalidade da situação da palavra. Os interlocutores então entendem e não entendem aí a mesma coisa nas mesmas palavras" (RANCIÈRE apud NATERCIA, 2005, p. 11-12).

Se na política antiga a ruptura dava-se somente pela noção de demos, ela hoje se prende ao "desdobramento de dispositivos de subjetivação do litígio (nós, cidadãos, nós, trabalhadores, nós mulheres)", só existindo sujeito político no conjunto de relações que o "nós e seu nome mantém com o conjunto das 'pessoas', o jogo completo das identidades e das alteridades implicadas na demonstração, e dos mundos, comuns ou separados, em que se definem" (RANCIÈRE apud NATERCIA, 2005, p. 69), mostrando-se mais claramente quando o nome dos sujeitos se separam do todo social.

É o que Rancière reconhece como sendo a pós-democracia, ou seja, a identificação entre democracia e Estado de direito servindo para produzir um regime de identidade a si da comunidade, para diluir a política sob um conceito de direito que a identifica ao espírito comunal, constituindo uma "mimesis estatal 
da prática política do litígio" (RANCIÈRE apud NATERCIA, 2005, p. 111). Com isso o Estado se legitima ao declarar impossível a política, pois o que caracteriza a "meta-polícia pós democrática", expressão utilizada pelo autor para definir a política contemporânea, é a relação da comunidade e da não comunidade do litígio. Assim, a exclusão hoje invoca a ausência da barreira representativa, com a pressuposição da inclusão de todas as partes e de seus problemas, que proíbe a subjetivação política de uma parcela dos sem-parcela. Com isso, todos estão incluídos de antemão, proibindo "a contagem dos incontados" (RANCIÈRE apud NATERCIA, 2005, p. 117) através do consenso. Nessa sociedade sem classes, a barreira é substituída por um continuum de posições, constituindo grande problema a falta de identidade ou vínculo social.

A isso equivalem novas formas de racismo e xenofobia, com o desemprego sendo um problema identitário, do imigrante que perdeu seu segundo nome e agora tem sua subjetivação através de uma pele, de uma cor, expondo sua alteridade nua e dando feição ao Outro Indefinivel, que suscita sentimentos do medo e da rejeição.

Para Rancière, essa mudança política, ainda em curso, resume-se no deslocamento de uma cena democrática para uma cena bumanitária. Ambas as cenas podem ser exemplificadas por suas subjetivações políticas decorrentes. No primeiro caso, declinaram formas polêmicas dos "homens nascidos livres e iguais em direitos"; o 'nós' tomou diferentes nomes pondo a prova a inscrição de igualdade proposta pelos direitos humanos: cidadãos, mulheres, proletários, negros e negras. Já na segunda cena, a frase igualitária deixa de ser citada no litígio de um dano, ou seja, os direitos do homem não são mais predicados políticos, mas sim identidade imediata e vitimada. É a figura excluída do logos, provido apenas da voz que "exprime uma queixa monótona, uma queixa do sofrimento nu que a saturação tornou inaudível [...]. 0 regime 'humanitário' da 'comunidade internacional' exerce quanto a elas a administração dos direitos do homem" (RANCIÈRE apud NATERCIA, 2005, p. 125).

Traçando essa ascendência da filosofia política, Rancière não pretende um pessimismo sistemático, mas sim posicioná-la a um lugar modesto da imodéstia: "a confrontação da humanidade nua e a desumanidade do humano" com 0

\footnotetext{
${ }^{4}$ A comunidade, para Rancière (1996, p. 69, 117), simboliza o mundo do dissentimento, não consensual, da heterogeneidade, de complexa articulação entre as diferenças, capaz de colocar em comum o não comum.
} 
pensamento político preso entre "as tenazes das políticas estatais da gestão e da polícia mundial do humanitário" (RANCIÈRE apud NATERCIA, 2005, p. 135). Difícil tarefa, que mostra o eclipse político atual, entre uma consensualidade feliz e de humanidade denegada, tornando seu futuro difícil de predizer ou decidir.

Em contrapartida, ainda segundo o autor, há "boas razões para pensar que ela [a política] não sairá nem da inflação identitária sobre as lógicas consensuais da divisão das parcelas, nem da hipérbole que convoca o pensamento a uma mundialidade mais originária ou a uma experiência mais radical da desumanidade do humano" (RANCIÈRE apud NATERCIA, 2005, p. 138). Ou ainda, seguindo seu raciocínio, há boas razões para acreditarmos que em uma política democrática a luta se trave entre aqueles que podem ter o direito à palavra e à razão.

Evocando o dissenso e a conflitualidade, Rancière pensa o desentendimento como algo que potencializa uma política em que a democracia seja meta e não sonho, desatrelada tanto do dano absoluto que vitimiza, quanto do consenso que a inviabiliza, neutralizando a diferença. A igualdade, nesse contexto, só existe através dos atos sempre precários que a constroem, não se devendo esperar das Declarações de direito que a efetivem por decreto.

Com base nas idéias de Rancière, pode-se pensar nas demandas identitárias expostas nos documentos federais de educação como constitutivas de um consenso ou de um dissenso? Seriam elas resultados de uma luta histórica contra a opressão e o racismo em busca de igualdade, ou mais um artifício da democracia bumanitária? Talvez todas essas coisas ao mesmo tempo. Para compreender a ambivalência dessas questões, recorremos a Michel Foucault.

\section{GENEALOGIA DO LIBERALISMO E AS LUTAS TRANSVERSAIS: DE QUEM É A VOZ?}

Operando de forma perspectiva e não geradora de sínteses, em que o poder é analisado de forma microfísica, operatória e circulante, podemos encontrar nos estudos de Michel Foucault sobre a atualidade dois grandes eixos que em seu pensamento se complementam, quais sejam, a constituição do sujeito e as artes de governar. 0 primeiro eixo implica três domínios que se articulam constantemente nas relações de poder (saber-poder e subjetivação), já no segundo, percebe-se um deslocamento para a concepção de governo das condutas, ou melhor, de uma governamentalidade. 
Foucault percebe, ao longo de suas pesquisas, as técnicas políticas (ciência do policiamento) transformadas em manifestações de poder que se vinculam ao processo de subjetivação (tecnologias do eu). Devido a isso, Foucault - ao decompor historicamente as "artes de governar" - sugere a utilidade de serem analisadas as técnicas de poder orientadas para indivíduos e destinadas a dirigi-los de forma contínua e permanente.

Esta política como "atividade" só é possível ser entendida a partir de uma noção de poder microfísica e operatória, não ideológica ou substancial. A partir disto, torna-se questão para Foucault, como o Estado político moderno assumiu predominância sobre a sociedade e passou a agir na esfera das menores partículas constitutivas do corpo social: os corpos dos indivíduos. Com isso, tem-se a conversão da política em Biopolítica, em que o foco não será somente uma anátomo-política do corpo humano, ou o "corpo como máquina”, mas também, o "corpo-espécie"; transpassado pela mecânica do ser vivo e como suporte dos processos biológicos: a proliferação, os nascimentos e a mortalidade, o nível de saúde, a duração da vida, a longevidade, com todas as condições que podem fazê-los variar, assumidos mediante toda uma série de intervenções e controles reguladores: uma biopolítica da população (FOUCAULT, 1984).

Na lição de 05 de janeiro de seu curso em 1983 Le Gouvernement de soi et des autres (FOUCAULT, 2008b), ao tecer considerações sobre seu "método", Foucault retoma temas que já se deparou em anos anteriores, como a loucura, a doença, a criminalidade e a sexualidade, para mostrar que lhe interessa buscar não os princípios ou eixos históricos, mas as marcas (repères), os lugares de experimentação, a história das veridicções, tratando-se de examinar, a loucura, por exemplo, como experiência no interior de nossa experiência, como lugar onde se formam diferentes saberes, discursos e práticas, tentando substituir a história da subjetividade por uma pragmática de si. Dessa forma, Foucault afasta seu trabalho tanto da história das mentalidades quanto da história das representações, acreditando que o essencial da história, passa pelo "buraco da agulha" (FOUCAULT, 2008b, p. 100).

Não trataremos aqui de todos os aspectos da filosofia de Foucault, mas nos interessa como, no seu curso de 1978/79 0 Nascimento da Biopolítica (FOUCAULT, 2008a), o autor estuda as experiências do liberalismo e da sociedade civil, como formas de poder e contra-poder que se articulam, reciprocamente. 
Nessa nova ênfase governamental que se dá entre os séculos XVII e XVIII, com a gestão das coisas e das pessoas, a prática de governo será atravessada pelo princípio: "governa-se sempre demais", ou pelo menos, segundo Foucault, é preciso sempre suspeitar de que se governa demais.

Tal seria o princípio do liberalismo, que se constituiu não por um direito legitimador exterior aos súditos/indivíduos, mas sim, pelos princípios de máximo e mínimo, próprios à economia política ou a racionalidade de mercado. Sendo assim, a reflexão liberal não parte da existência do Estado, mas da sociedade que se apresenta em relação complexa de "exterioridade" e "interioridade" em relação a ele; é essa sociedade que permite inverter a questão: como governar mais pelo menor custo possível? Por outra: por que é preciso governar?

Nesse sentido, o liberalismo não deve ser entendido como uma utopia que não se realizou, mas como uma governamentalidade que se opõe à anterior, evitando seus abusos, de forma que se pode encontrá-lo "sob formas diferentes mas simultâneas, como esquema regulador da prática governamental e como tema de oposição às vezes radical”(FOUCAULT, 2008a, p. 434).

Ao seguir esse raciocínio analítico, entende-se o liberalismo como um "novo tipo de racionalidade na arte de governar, esse novo tipo de cálculo que consiste em dizer e em fazer o governo dizer 'aceito, quero, projeto, calculo que não se deve mexer em nada disso" (FOUCAULT, 2008a, p. 28).

Foucault investigou os elementos da "crise no dispositivo de governamentalidade" (FOUCAULT, 2008a, p. 95), aliando as crises do capitalismo e, por decorrência, as crises do liberalismo, tentando entender (e não interpretar, como ele próprio pondera) como o neoliberalismo surgido em Chicago e o ordoliberalismo alemão, formam-se como respostas a essas crises.

$\mathrm{Na}$ aula de 07 de Março daquele ano, Foucault estuda o caso do neoliberalismo francês e percebe como este segue os princípios neo/ordo liberais em que "a economia é essencialmente um jogo" (FOUCAULT, 2008a, p. 277), desenvolvido entre parceiros, mas que a sociedade inteira deve ser permeada e se inserir, seja pelo assistencialismo (que ataca os efeitos e não a razão da pobreza) ou pela gestão empreendedora, nesse jogo econômico.

Não há um fora, e o "Estado tem por função essencial definir as regras econômicas do jogo e garantir que sejam efetivamente bem aplicadas. Quais são essas regras? Elas devem ser tais que o jogo econômico seja o mais ativo possível, que beneficie, por conseguinte, o maior número possível de pessoas", como 
um novo contrato social, que modificará as relações entre tudo que havia sido elaborado pela política ocidental, havia séculos (FOUCAULT, 2008a, p. 278-282).

Nesse contexto, a sociedade civil assume vital importância, na medida em que, segundo Foucault, o que caracteriza a racionalidade liberal, a regulagem do governo pela racionalidade, se dá "no princípio de regulamentação da arte de governar no comportamento racional dos que são governados" (FOUCAULT, 2008a, p. 423). Esse seria o ponto de clivagem: não que tenham desaparecido outras formas de poder em que se governava através da verdade (seja religiosa ou jurídica), mas agora temos, a partir do século XIX, toda uma série de racionalidades governamentais (verdade, Estado soberano, agentes econômicos, os próprios governados) que se "acavalam, se apóiam, se contestam, se combatem, se combatem reciprocamente" constituindo a política, definida por Foucault como sendo, ao mesmo tempo, "o jogo dessas diferentes artes de governar com seus diferentes indexadores e o debate que essas artes de governar suscitam" (FOUCAULT, 2008a, p. 424).

A partir desse ponto, como podemos compreender as lutas contemporâneas, geradoras de discursos, materialidades e práticas percebidas, por exemplo, nos currículos escolares?

Foucault (1995, p. 234-236), chamava tais lutas de transversais atribuindolhes uma imediaticidade não limitadas a um local e nem se opondo a um único inimigo. São também específicas, constituindo-se como batalhas contrárias às subjetivações abstratas que nos dizem o que somos através de um regime de saber. Contrárias tanto às formas de dominação (étnica, social e religiosa) e às formas de exploração (que separa indivíduo daquilo que produz), quanto a tudo o que liga os indivíduos a si, submetendo-os e subjugando-os.

Percebe-se, com Foucault, que ao supor a inexistência dos universais abstratos, somos concebidos como um construto histórico das subjetivações, que classifica através de saberes-poderes os que "não se adaptam" à norma estabelecida como os anormais: deficitários, delinquentes, pervertidos, loucos etc. Porém, são com esses "anormais" que estabelecemos relação constitutiva com o que somos, ou melhor, com o que nos tornamos.

Conforme Márcio Alves da Fonseca, as análises de Foucault sobre a arte de governar neoliberal talvez nos permitam identificar marcas importantes da atualidade, afinal "no contexto desta arte de governar, a política encontrase reduzida a uma racionalidade econômica, e, desse modo, é pensada segundo 
critérios essencialmente técnicos" (FONSECA, 2008, p. 160-161). Sendo assim, 0 indivíduo comum não seria o adequado para intervir. Seria necessário, ainda segundo Fonseca, "avançar em uma análise que seja capaz de desfibrar a racionalidade política que a constitui, o que implica identificar sua gênese, descrever seu funcionamento e, assim também, indicar as brechas para 0 surgimento das 'contra-condutas' que a ela podem se opor" (FONSECA, 2008, p. 161).

Comovimos, apolíticaé,paraFoucault, aquiloquenascecomo afrontamento às governamentalidades. Em sua compreensão das relações biopolíticas, Foucault estabelece as relações de poder e as estratégias de insubmissão como constitutivas, pois, é a partir delas que o poder é constituído e reconstituído, não apresentando uma essência ou sendo exterior aos sujeitos. Por isso que, no caso do liberalismo, a sociedade civil e suas possíveis insubordinações criam novas racionalidades de governo, pelo máximo ou pelo mínimo. Interessante análise quando constatamos que todos os documentos federais citados sobre as diversidades étnicas/culturais só são possíveis a partir da redemocratização do país, em que Movimentos Sociais que já lutavam há tempos, tem direito à voz.

Podemos aqui tentar fazer uma ligação entre a análise de Foucault e a noção de desentendimento de Rancière, pois, para ambos - embora partindo de perspectivas analíticas e metodológicas diferenciadas - a política tornouse assunto de especialistas, e os governados, para o primeiro ou, o demos para o segundo, não tem direito à palavra pública, na cena política. No máximo, segundo Foucault, é-lhes permitido a "indignação lírica", então, como é possível a resistência?

\section{"Em Face aos Governos, os Direitos do Homem": O Grito e A ReFleX̃̃o}

Foucault escreve um pequeno manifesto, em 1981, por ocasião do incidente internacional, o boat people, que mostrou o descaso e a violência que algumas pessoas do sudeste asiático sofriam, ao tentarem escapar de forma ilegal de seus países de origem, em busca de melhores condições de vida.

Contrário a esse abandono, Foucault redige o texto "Face aux gouvernements, les droits de l'homme" (FOUCAULT, 2001, p. 1526-1527), que foi publicado no Liberátion, alguns dias depois de sua morte, em 1984. 
Nessa ocasião, Foucault enaltece "os indivíduos privados", não comissionados por ninguém para estarem juntos, que se uniram para "falar", de uma certa dificuldade compartilhada em "suportar" o que está acontecendo, arrogando três princípios fundamentais que guiam tal iniciativa:

Uma cidadania universal, com seus direitos e deveres, que se erga contra qualquer abuso de poder, pois somos todos governados e, por isso, solidários.

0 Infortúnio dos homens não deve jamais ser um resto mudo da política, ele funda um direito absoluto de se levantar contra os poderosos, que são sim responsáveis por tais infortúnios.

Temos que rejeitar uma divisão do trabalho que propõe aos governos a ação e reflexão e aos governados somente a indignação. Com frequência são os que governam os que falam. Esse teatro da indignação tem que mudar (FOUCAULT, 2001, p. 1526-1527).

Para Oswaldo Giacóia Junior (2008, p. 303), trata-se aqui de um "direito novo" proposto por Foucault, "não contaminado pelo princípio da soberania, ao mesmo tempo antidisciplinar e não previdenciário - um direito não estatal, amparado numa insólita cidadania internacional fundada nos abusos do poder e na condição infeliz das vítimas desse abuso, quaisquer que sejam”.

Foucault não acreditava em simples substituições de poder, mas sim, nas lutas diárias, de resistências, contra os abusos deste. Assim, o direito real à indignação, com a coragem da fala pública respeitada e ouvida, é uma necessidade política contrária aos excessos governamentais. Caberia então, de acordo com suas análises no curso de 1978/79, entendermos as insurgências advindas da sociedade civil para entendermos 0 próprio poder. Munidos das análises de Rancière e Foucault, podemos retornar às questões da diversidade cultural na educação brasileira.

\section{Lutas Pelo Currículo: Polifonia das Vozes}

É um pressuposto, na presente análise, que as questões curriculares são um campo de luta, uma plataforma de disputa em que poderes e contra-poderes articulam-se, de forma agonística (combativa), e não geradoras de sínteses.

Conforme afirmado anteriormente, as lutas contemporâneas tendem, cada vez mais, à inserção de questões identitárias na política. 
Seguindo as análises de Rancière, percebe-se como a política tem se tornado território do consenso, ao abarcar todas as demandas sociais, impedindo o conflito. Semelhante diagnóstico pode ser atribuído a Foucault, para quem a governamentalidade significa um cálculo de poder dos governados, destarte, nada, ou quase nada escape a essa racionalidade vinculada, atualmente, ao jogo mercantil.

Dentro desse cenário, como se pode entender as demandas pela inserção de temas vinculados à identidade (raça, gênero, religião, etnia etc.) na educação brasileira? Nessa dinâmica, uma alteração nos materiais didáticos e nos propósitos educacionais brasileiros era, e continua sendo, necessária para que muitas arbitrariedades contra grupos específicos, principalmente, negros e indígenas, sejam superadas. 0 que não parece tão notório é a naturalização de um discurso que tem como principais demandas o reconhecimento identitário, as diferenças culturais, o esforço pela racialização dos alunos, somente, sem levar em conta o esvaziamento político que pode decorrer daí, ao transformar lutas dos semparcelas em questões governamentais.

Isso não significa que sejamos contrários às conquistas estabelecidas em torno de demandas identitárias, mas que precisamos evitar uma ingenuidade teórica, que nos leve a uma celebração acrítica e evite-nos perceber o caráter ambivalente "dessa bifrontalidade de todo o fenômeno histórico e político, um combate no campo das conquistas representadas pelos Direitos Humanos" (GIACÓIA JUNIOR, 2008, p. 295).

Os debates que permeiam a questão parecem hoje, divididos entre dois discursos principais (mas não únicos): os celebratórios - que identificam as questões da diversidade cultural como algo tardiamente conquistado, acusando de racismo e preconceito todos os que as criticam - e os igualitários radicais - que concebem as questões multiculturalistas na educação como forma de desvio da questão de classe e/ou de uma cidadania plena.

Não se trata, aqui, de indicar um meio-termo, um acordo ou escolher uma das tendências, mas de marcar os documentos federais citados como materialidades discursivas em que esses posicionamentos se interpõem de forma não maniqueísta. Não se propõem aqui sínteses conciliatórias, mas uma atitude crítica sob esse fenômeno da atualidade que se verifica nas conquistas suscitadas pelos documentos federais de nossa educação. Para tanto, sugere-se que pensemos a questão da diversidade cultural no currículo escolar a partir de algumas, dentre 
inúmeras possíveis, questões para a reflexão. Intenciona-se, com elas, retomar as análises de Rancière e Foucault, visando a desnaturalização de nosso olhar para esse fenômeno complexo, ambivalente, heterogêneo. Vamos a elas:

Pode-se assinalar a inserção de demandas identitárias como fruto de um consenso ou de um cálculo governamental, para que as minorias "calem-se" frente às conquistas?

A inserção das questões diferencialistas na educação é uma etapa de um processo maior de conquistas em torno dessas demandas?;

A conquista de um "novo direito" frente aos governos só pode se dar com 0 uso público da palavra, a reflexão e ação, não somente com a "queixa monótona". Assim, os documentos podem ser vistos como materialidade de uma ação contrária à discriminaç̧ão?;

A real indignação e as brechas no poder que ela ocasiona só podem ocorrer com um posicionamento crítico, a fim de entendermos como essas questões, no caso, a inserção curricular da diferença no âmbito educacional, está nos constituindo de outra forma?;

Pode-se pensar em indignações que não estejam atreladas, politicamente, a identidades essencialistas como o negro, a mulher, o homossexual, o islâmico, etc?

Evitando-se maniqueísmos, pode-se buscar, de forma crítica e analítica, uma ontologia de nós mesmos, percebendo quais as implicações entre governo e governados, propostas pelos documentos sobre pluralidade cultural?

Sem prescindirmos dos ganhos reais e das lutas visando à igualdade, que parecem permear a todos os movimentos diferencialistas ou identitários, fazse necessário indagarmos as formações discursivas em torno dessa instituição privilegiada na formação dos sujeitos em que a escola se constitui.

Se um deslocamento parece latente na cena política, é preciso investigarmos com acuidade essa transformação profunda que parece se dar nas relações de poder, na cena política (ou na ausência dela) para, quem sabe, formarmos relações mais suportáveis, arrancando aos governos o monopólio da fala e da reflexão sobre 0 que somos, dia a dia. 


\section{REFERÊNCIAS}

BRASIL. Secretaria de Educação Fundamental. Parâmetros Curriculares Nacionais: terceiro e quarto ciclos: apresentação dos temas transversais. Brasília: MEC, 1998.

. Ministério da Educação. Resolução no 1, de 17 de junho de 2004. Diretrizes curriculares nacionais para a educação das relações étnico-raciais e para o ensino de história e cultura afro-brasileira e africana. Brasília: MEC, 2004.

Secretaria de Educação Básica. Programa ética e cidadania: construindo valores na escola e na sociedade: relações étnico-raciais e de gênero Brasília: Ministério da Educação, 2007. (Módulo 1: Ética).

FONSECA, Márcio Alves. Para pensar o público e o privado: Foucault e o tema das artes de governar In: RAGO, Margareth; VEIGA-NETO, Alfredo (Org.). Figuras de Foucault. 2. ed. Belo Horizonte: Autêntica, 2008. p. 155-163

FOUCAULT, Michel. A história da sexualidade I: a vontade de saber. 5. ed. Rio de Janeiro: Graal, 1984.

O sujeito e o poder. In: DREYFUS, H. L.; RABINOW, P. Michel Foucault: uma trajetória filosófica, para além do estruturalismo e da hermenêutica. Rio de Janeiro: Forense Universitária, 1995.

Face aux gouvernements, lês droits de l'homme. In: Dits et écrits II: 1976-1988. Paris: Quarto Gallimard, 2001.

. Nascimento da biopolítica: curso dado no collège de France (19781979). São Paulo: Martins Fontes, 2008a. (Coleção Tópicos).

. Le Gouvernement de soi et des autres: cours au collège de France 1982-1983. Paris: Gallimard, 2008b.

GIACÓIA JUNIOR, Oswaldo. Sobre direitos humanos na era da bio-política. Kriterion, Belo Horizonte, v. 49, n. 118, p. 267-308, 2008. Disponível em: <http:// www.scielo.br/scielo.php?script=sci_arttext\&pid=S0100-512X2008000200002>. Acesso em: 23 nov. 2009.

NATERCIA, Flávia. Em nome do dissenso, filósofo francês redefine termos e conceitos na arte e na política. Ciência e Cultura, São Paula, v. 57, n. 4, p. 1616, 2005. Disponível em: <http://cienciaecultura.bvs.br/scielo.php?pid=S000967252005000400011\&script=sci_arttext $>$. Acesso em: 17 nov. 2009.

RANCIÈRE, Jacques. O desentendimento: política e filosofia. São Paulo: Ed. 34, 1996. (Coleção TRANS). 